\title{
THE EFFICACY OF PROGESTERONE IN TREATMENT OF TRAUMATIC OPTIC NEUROPATHY (PROTON STUDY)
}

\author{
Saran Jiranansiri*, Somboon Panyakorn*, Kreaingsak Sirisakpanich **, Raveewan Choontanom* \\ *Department of Ophthalmology, Phramongkutklao College of Medicine, Bangkok, Thailand \\ **Department of Obstetrics and Gynecology, Phramongkutklao College of Medicine, Bangkok, Thailand
}

\begin{abstract}
To evaluate the visual function improvement by progesterone for treatment of indirect traumatic optic neuropathy Study design was comparative historical controlled trial. Seven patients newly diagnosed with indirect traumatic optic neuropathy (TON) were enrolled for progesterone group. Nineteen indirect TON patients were reviewed medical records for steroid group $(\mathrm{N}=12)$ and observation group $(\mathrm{N}=7)$. Patients in progesterone group were given Depot medroxyprogesterone acetate (DMPA) $1 \mathrm{mg} / \mathrm{kg}$. intramuscular injection every $12 \mathrm{hrs}$. for 5 days and observed for side effects. All patients were examined and reviewed for visual acuity by ETDRS chart, color vision test by Ishihara test, visual field testing by Humphrey automated perimetry, fundus and optic disc examination at baseline, follow-up 1 week, 1 month and 3 months. Demographic and clinical characteristic of patients in 3 groups were not different in terms of age, sex, underlying disease, side of eye, type of injury, baseline visual acuity, associated orbital fracture, history of amnesia, time to visit hospital and time to start treatment. Improvement in best-corrected visual acuity (BCVA) compared at 3 months from baseline showed no difference between 3 groups ( $p=0.891$ ). Analysis within steroid group showed statistically significant improvement of BCVA at 1 and 3 months ( $p=0.015,0.028$ respectively). No improvement was shown in color vision and visual field in progesterone group. Only better baseline BCVA was the protective factor for better visual outcome $(p=0.027$, Odds ratio $=0.004$, $95 \% \mathrm{CI}=0.000-0.537)$. No side effects of progesterone were found in this study. Progesterone is a safe and promising neuroprotective agent that could be adjunctive or alternative to steroid in case of contraindication to corticosteroid treatment. This study showed no difference among choices of treatment therefore study in larger population is required. Steroid remains an effective option contrast with recent studies.
\end{abstract}

Keywords : Visual function, Optic neuropathy

J Southeast Asian Med Res 2017;1:12-19.

http://www.jseamed.org

\section{Correspondence to:}

Choontanom R, Department of Ophthalmology, Phramongkutklao College of Medicine, Bangkok, Thailand E-mail : ravee_choon@yahoo.com 


\section{Introduction}

IntroductionTraumatic optic neuropathy (TON) is a rare condition found $2.3 \%$ of head injury ${ }^{(1)}$ but often devastating cause of permanent visual loss after blunt or penetrating injury. While projectiles or other sharp objects injure the optic nerve directly, the most common form of traumatic optic neuropathy is indirect, as a result of concussive force to the head, particularly the forehead. ${ }^{(2)}$ This impact is thought to transmit a shock wave to the optic canal, damaging the optic nerve. ${ }^{(3)}$ In some cases a relatively mild concussive impact can result in indirect traumatic optic neuropathy. Typically, the retina and optic disc initially appear normal, and the only objective finding is the presence of a relative afferent pupillary defect. The severity and range of the initial visual loss can vary widely. Optic atrophy does not become apparent for 3 - 4 weeks. ${ }^{(4)}$ While the diagnosis of indirect traumatic optic neuropathy can usually be made with the aid of a careful history and examination; its optimal management is far less well defined. Evidence for the relative benefits of these approaches has mainly been based on small retrospective studies, and there fore a convincing rationale for treatment is lacking. The management of traumatic optic neuropathy (TON) is controversial. Various options include high - dose or low - dose corticosteroids, immediate decompression of the canalicular portion of the optic nerve (via intracranial, transethmoidal, endonasal, sublabial, or other approaches), decompression of the canalicular optic nerve after a course of systemic corticosteroids, opticnerve sheath fenestration and observation. ${ }^{(5,6)} \mathrm{A}$ comparative nonrandomized interventional study found no clear benefit for either corticosteroid therapy, optic canal decompression, or observation in the treatment of TON ${ }^{(7)}$ Progesterone is a hormone which has steroidal, neuroactive and neurosteroidal action in the central neuronal system. Neuroprotective effects of progesterone have recently been shown in a variety of animal models, including ischemic and traumatic brain insult models. ${ }^{(8,9)}$ Postinjury administration of progesterone in experimental models of head injury confers significant protection against TBI - induced cerebral edema and secondary neuronal death, promoting behavioral recovery.
Experimental evidence suggests that postinjury treatment with progesterone decreases brain edema, attenuates free radical damage, and reduces neuronal loss in TBI animal models. Progesterone also reduces the inflammatory response and attenuates neurological abnormalities after ischemia and spinal cord injury. ${ }^{(10-35)}$ In a recently published controlled study of progesterone, Wright and colleagues conducted a phase II, randomized, double-blind, placebo controlled trial to assess the safety and benefit of administering progesterone to patients with acute TBI. ${ }^{(36)}$ No serious adverse events were found in the 77 patients who received progesterone, and the patients with moderate TBI who received progesterone were more likely to have a moderate to good outcome than those were randomized to placebo at 30 days post injury. This outcome suggests that progesterone causes no harms and may be a beneficial treatment for TBI. ${ }^{(36-38)}$

The optic nerve is the second of twelve paired cranial nerves and is technically part of the central nervous system, ensheathed in all three meningeal layers (dura, arachnoid, and pia mater). The fibers of the optic nerve are covered with myelin produced by oligodendrocytes rather than Schwann cells of the peripheral nervous system, and are encased within the meninges. Despite potential advantages and the good safety profile of progesterone described in studies utilizing animals or humans as subjects, there is relatively no clinical information available for assessing neuroprotective properties of progesterone in the patients with traumatic optic neuropathy. The purpose of the present pilot clinical study was to assess the longer-term efficacy of progesterone on improving the visual outcome of patients with indirect traumatic optic neuropathy.

\section{Methods}

The study was conducted in compliance with the clinical protocol approved by the Institutional Review Board of Royal Thai Army Medical Department. Protocol was followed as in flow chart Fig 1.

\section{Participant selection}

All of newly diagnosed indirect traumatic optic neuropathy patients visited at Phramongkutklao hospital were enrolled during February to August 2015. Male or female patients between the ages of 18 and 65 years were studied. 
The patients received progesterone within 8 hours after the documented time of injury.

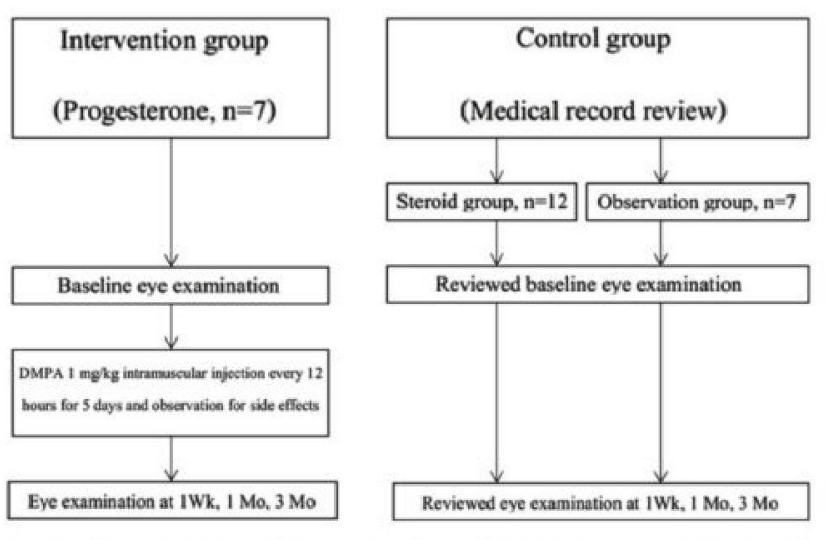

Fig1. Flow chart indicating patient allocation, intervention and follow-up

Inclusion criteria

1. Male or female patient, aged 18 - 65 years old.

2. Diagnosed with indirect traumatic optic neuropathy within 7 days

3. No other ocular or visual pathway effecting visual function

Exclusion criteria

1. Low level of consciousness and unable to evaluated visual acuity

2. Other system injury such as cardiovascular, pulmonary injury

3. Progesterone administration with in 30 days

4. Contraindicated to progesterone as following

1) Pregnancy or lactation

2) Abnormal vaginal bleeding

3) Breast mass or history of breasteancer

4) Uncontrolled blood pressure $>180 / 110 \mathrm{mmHg}$.

5) Diabetes mellitus with complications

6) Diagnosed or history of is chemic heart disease

7) Occlusive vascular diseases

8) Active viral hepatitis, cirrhosis, liver cancer

9) Coagulopathy, deep vein thrombosis, pulmonary embolism

Screening for eligible subjects

After informed consents were obtained, participants were examined and investigated for eligible subject indicated for drug administration.
1. Blood pressure

2. Complete blood count, Coagulograms, Fasting plasma glucose, Liver function test

3. Electrocardiogram

4. For female patient: History taking about menstrual period, contraception, abnormal vaginal bleeding, urine pregnancy test, complete breast exam

1) Age 18 - 39 years old: Ultrasound breast

2) Age 40 - 65 years old: Mammogram

\section{Baseline eye examination}

All patients in progesterone group were examined as following for comparing to follow-up eye examination

1. Visual acuity by Early Treatment Diabetic Retinopathy Study (ETDRS) chart

2. Fundus and optic disc examination

3. Color vision test by Ishihara test

4. Visual field testing by Humphreyautomated perimetry (Swedish Interactive Threshold Algorithm (SITA) standard program 30 - 2)

Patients in steroid and observation groups were review medical record for visual acuity for baseline data.

Drug administration All eligible subject in progesterone group diagnosed with indirect traumatic optic neuropathy within 7 days were received Depot medroxy progesterone acetate (DMPA) $1 \mathrm{mg} / \mathrm{kg}$ intramuscular injection every 12 hours for 5 days either outpatient or inpatient. All patients received the medication were observed for side effects such as headache, fatigue, nausea, vomiting, hair loss, weight gain/ loss, depression, abnormal menstruation and vaginal bleeding.

Follow up Patients in progesterone group were followed up and examined same as baseline eye examination at 1 week, 1 month and 3 months from last time of drug administration and also screened for side effects, physical examination and laboratory testing as following at 1 and 3 months

1. Blood pressure

2. Complete blood count,

Coagulograms, Fasting plasma glucose, Liver function test

Patients in steroid and observation group were also reviewed for visual acuity at approximate time of follow-up at 1 week, 1 month and 3 months.

\section{Statistical analyses}

For evaluating visual improvement, visual acuities were converted to logarithm of the minimum angle of resolution ( $\log$ MAR) equivalents. 
Poor visual acuity was assumed as the following: No light perception $=1.9$, Light perception $=1.8$, Hand motion $=1.7$, Counting finger $=1.6$ for purpose of analysis. Recovery of visual acuity was defined as a decrease of at least $0.4 \log$ MAR in visual acuity after 3 months. We compared clinical characteristics of patients in each group and improvement of visual acuity in different groups by chi-square test, and we used $t$-test and paired $t$-test for comparison of initial and final mean visual acuities in those groups. The effect of treatment on final BCVA was evaluated by ANOVA test after adjustment for confounding factors. Statistical level of significance was set at 0.05 .

\section{Results}

Seven patients newly diagnosed with indirect traumatic optic neuropathy were enrolled for progesterone group. Table 1 demonstrates basic characteristic data of all patients in progesterone group. All patients in this group were male and mean age was $34.29 \pm 16.19$ years (range from 20 to 61 years). No side effect of progesterone was found in patient received progesterone. Nineteen indirect TON patients were reviewed medical records for steroid group $(\mathrm{N}=12)$ and observation group $(\mathrm{N}=7)$. Demographic and clinical characteristic of patients in 3 groups were not different in terms of age, sex, underlying disease, side of eye, type of injury, baseline visual acuity, associated orbital fracture, history of amnesia, time to visit hospital and time to start treatment.

Table 1 Basic characteristic of patients in progesterone

\begin{tabular}{|c|c|c|c|c|c|c|c|c|c|}
\hline Prisere & $\operatorname{sex}$ & $\begin{array}{l}A \mathrm{Be} \\
(\mathrm{ys})\end{array}$ & Eye & $\begin{array}{l}\text { Type of } \\
\text { injury }\end{array}$ & $\begin{array}{l}\text { Initial } \\
\text { BCVNA }\end{array}$ & $\begin{array}{l}\text { Final } \\
\text { BCVA }\end{array}$ & $\begin{array}{l}\text { Dise } \\
\text { palor }\end{array}$ & $\begin{array}{l}\text { Side } \\
\text { effletert }\end{array}$ & Medications \\
\hline 1 & M & 24 & LE & VA & $20 / 125$ & 2020 & 3Mo & No & 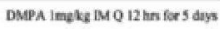 \\
\hline 2 & м & 94 & RE & Fall & HМ & HМ & IMo & No & 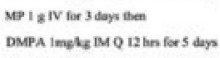 \\
\hline 3 & м & 27 & RE & VA & NPL & PL. & IMo & No & DMPA Ime $4 \mathrm{~L}$ MQ 12 ind for 5 deps \\
\hline 4 & M & 26 & LE & VA & PL. & $20 / 200$ & $3 M_{0}$ & No & 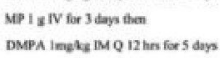 \\
\hline 5 & м & 28 & LE & $v_{A}$ & нм & CF & IMo & No & 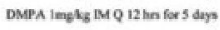 \\
\hline 6 & м & 20 & LE & $V_{A}$ & NPL & PL & IMo & No & 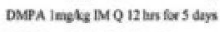 \\
\hline$?$ & м & 61 & $L E$ & Fall & NPL & NPL & IMo & No & 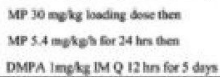 \\
\hline
\end{tabular}

$\mathrm{BCVA}=$ Best-corrected visual acuity, $\mathrm{M}=$ Male, $\mathrm{RE}=$ Right eye, $\mathrm{LE}=$ Left eye, $\mathrm{VA}=$ Vehicle accident, NPL $=$ No light perception, $\mathrm{PL}=$ Light perception, $\mathrm{HM}=$ Hand motion, $\mathrm{CF}=$ Counting finger, DMPA=Depot medroxy progesterone acetate, MP = Methylprednisolone, IV = intravenous, IM = intramuscular, $\mathrm{Q}=$ every, $\mathrm{Mo}=$ month.
Table 2 Demographic and clinical characteristic

\begin{tabular}{|c|c|c|c|c|c|}
\hline Characteristics. & $\begin{array}{c}\text { Progesterone } \\
n=7\end{array}$ & $\begin{array}{c}\text { Stervid } \\
\mathrm{n}=12\end{array}$ & $\begin{array}{c}\text { Observation } \\
n=7\end{array}$ & $\begin{array}{l}\text { Total } \\
\mathrm{n}=26\end{array}$ & P-value \\
\hline Age, mean (SD) & $34.29(16.19)$ & $25.58(11.30)$ & $39.14(18.89)$ & $31.58(15.56)$ & 0.163 \\
\hline Sex Male, n(96) & $7(100)$ & $11(91.7)$ & $6(85.5)$ & $24(92.3)$ & 0.601 \\
\hline Female, al $\%$ ) & $0(0)$ & $1(8.3)$ & $1(14.3)$ & $2(7.7)$ & \\
\hline Eye RE, n(\%) & $2(28,6)$ & $3(25,0)$ & $3(42.9)$ & $8(30,7)$ & 0.711 \\
\hline $\mathrm{LE}, \mathrm{n}(\%)$ & $5(71.4)$ & $9(75.0)$ & $4(57.1)$ & $18(69.2)$ & \\
\hline \multicolumn{6}{|l|}{ Injury type, a(\%) } \\
\hline Vehicle accident & $5(71.4)$ & $11(91.7)$ & $2(28.6)$ & $18(69.2)$ & 0.055 \\
\hline Fall & $2(28.6)$ & $0(0)$ & $2(28.6)$ & $4(15,4)$ & \\
\hline Asaault & $0(0)$ & $1(8.3)$ & $1(14.3)$ & $2(7.7)$ & \\
\hline Blast injury & $0(0)$ & $0(0)$ & $2(28.6)$ & $2(7.7)$ & \\
\hline \multicolumn{6}{|l|}{ Baseline BCVA,n(\%) } \\
\hline NPL & 3.(42.9) & $5(41.7)$ & $0(0)$ & $8(30.8)$ & 0.554 \\
\hline $\mathrm{PL}$ & $1(14.3)$ & $2(16.7)$ & $2(28.6)$ & $5(19.2)$ & \\
\hline нм & $2(28.6)$ & $1(8.3)$ & $2(28.6)$ & $5(19.2)$ & \\
\hline $20 / 200-\mathrm{CF}$ & $0(0)$ & $3(25.0)$ & $2(28.6)$ & $5(19.2)$ & \\
\hline $20 / 40 \geq 20 / 200$ & $1(14.3)$ & $1(8.3)$ & $1(14.3)$ & $3(11.5)$ & \\
\hline$\geq 2040$ & $0(0)$ & $0(0)$ & $0(0)$ & $0(0)$ & \\
\hline \multicolumn{6}{|c|}{ Categorized baseline BCVA, n(\%) } \\
\hline$\leq \mathrm{HM}$ & $6(85.7)$ & $8(66,7)$ & $4(57.1)$ & $18(69.2)$ & 0.494 \\
\hline$>\mathrm{HM}$ & $1(14,3)$ & $4(33,3)$ & $3(42.9)$ & $8(30.8)$ & \\
\hline $\begin{array}{l}\text { Time wo visit hospital, Hr. } \\
\text { (SD) }\end{array}$ & $8.71(5.59)$ & $3.92(2.91)$ & $9.29(10.19)$ & $6.65(6.55)$ & 0.141 \\
\hline $\begin{array}{l}\text { Time to treatment, Hr. } \\
\text { (SD) }\end{array}$ & $82.71(56.36)$ & $61.08(44.88)$ & * & $69.05(49.04)$ & 0.369 \\
\hline \multicolumn{6}{|l|}{ Underlying DM, n(\%) } \\
\hline Yes & $1(14.3)$ & $1(8.3)$ & $1(14.3)$ & $3(11.5)$ & 0.894 \\
\hline No & $6(85.7)$ & $11(91.7)$ & $6(85.7)$ & $23(8.8 .5)$ & \\
\hline \multicolumn{6}{|l|}{ Underlying $\mathrm{HT}, \mathrm{n}(\%)$} \\
\hline Yes & $1(143)$ & $1(8.3)$ & $1(14.3)$ & $3(11.5)$ & 0.894 \\
\hline No & $6(85.7)$ & $11(91.7)$ & $6(85.7)$ & $23(88.5)$ & \\
\hline \multicolumn{6}{|l|}{ Underlying DLP, n(\%) } \\
\hline Yes & $0(0)$ & $1(8.3)$ & $0(0)$ & $1(3.8)$ & 0.545 \\
\hline No & $7(100)$ & $11(91.7)$ & $7(100)$ & $25(96.2)$ & \\
\hline \multicolumn{6}{|l|}{ Orbital wall fracture, n(\%) } \\
\hline No & $9(71.4)$ & $4(33.3)$ & $5(71.4)$ & $14(53.8)$ & 0.272 \\
\hline I wall & $1(14.3)$ & $1(8.3)$ & $0(0)$ & $2(7.7)$ & \\
\hline$>1$ walls & $1(14.3)$ & $7(58.3)$ & $2(28.6)$ & $10(38.5)$ & \\
\hline \multicolumn{6}{|l|}{ History of amnesia, n(\%) } \\
\hline Yes & $5(71.4)$ & $9(75.0)$ & $4(57.1)$ & $18(69.2)$ & 0.711 \\
\hline No & $2(28.6)$ & $3(25.0)$ & $3(42.9)$ & $8(30.8)$ & \\
\hline \multicolumn{6}{|c|}{ Development of disc palor, n(\%) } \\
\hline IWk & $0(0)$ & $\theta(0)$ & $0(0)$ & $0(0)$ & 0.196 \\
\hline IMo & $5(71.4)$ & $8(66.7)$ & $3(42.9)$ & $16(61.5)$ & \\
\hline $3 \mathrm{Mo}$ & $2(28.6)$ & $4(33.3)$ & $2(28.6)$ & $8(30.8)$ & \\
\hline$>3 M_{0}$ & $0(0)$ & $0(0)$ & $2(28.6)$ & $2(7.7)$ & \\
\hline
\end{tabular}

$\mathrm{BCVA}=$ Best-corrected visual acuity, $\mathrm{RE}=$ Right eye, $\mathrm{LE}=\mathrm{Left}$ eye, $\mathrm{VA}=$ Vehicle accident, NPL $=$ No light perception, $\mathrm{PL}=$ Light perception, $\mathrm{HM}=$ Hand motion, $\mathrm{CF}=$ Counting finger, $\mathrm{DM}=$ Diabetes mellitus, $\mathrm{HT}=$ Hypertension, DLP = Dyslipidemia

An interesting case example of a patient in progesterone group, showing a surprising visual improvement in many parameters: A 24 year-old Thai male with history of motorcycle accident and forehead contusion came to hospital with symptom of blurred vision on his left eye after the accident. Initial best-corrected visual acuity of his left eye was 20/125, positive relative afferent pupillary defect on left eye. Neuroimaging showed no abnormalities. He was diagnosed with indirect traumatic optic neuropathy and enrolled to the study. He was given Depot medroxyprogesterone acetate $1 \mathrm{mg} / \mathrm{kg}$ intramuscular injection every 12 hours for 5 days and no side effects were observed. 
After follow-up, the final best-corrected visual acuity at 3 months was 20/20. There was persistently positive relative afferent pupillary defeet on left eye and optic disc photography showed left optic nerve atrophy developed in 3 months Fig 2. Color vision test showed increased in number of plate from 0 plate at baseline, 12 plates at 1 week and 25 plates at both 1 and 3 months of follow-up. Visual field testing showed improvement in mean deviation and pattern standard deviation demonstrated by the gray scale in Fig 2.

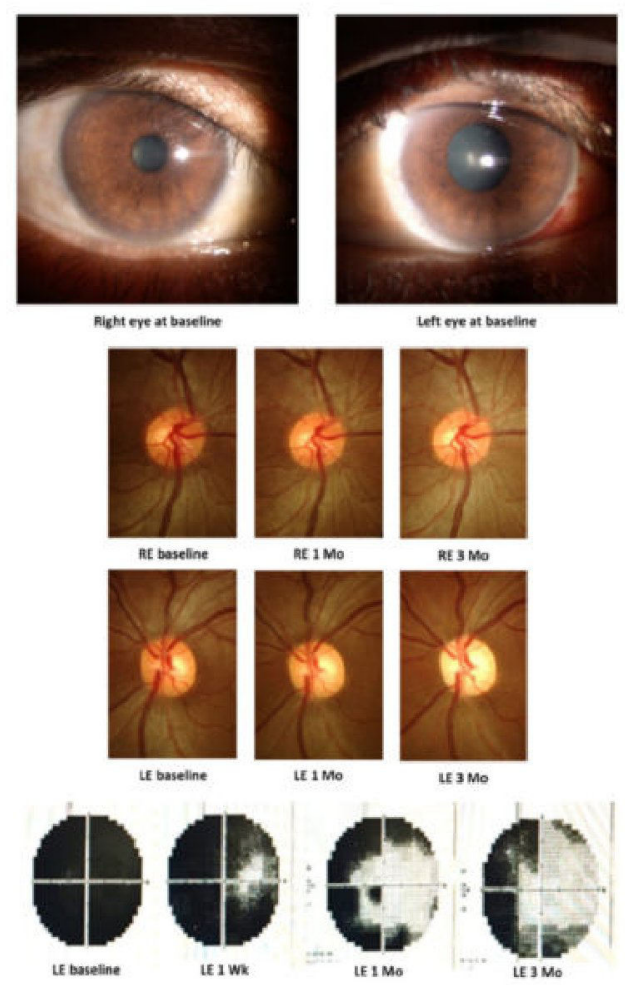

Fig. 2 Patient example: Patient number 1: Anterior segment photograph at baseline, disc photograph and gray scale of visual field test during follow-ups.

Repeated measure ANOVA was utilized for analysis of improvement in best-corrected visual acuity after adjustment for confounding factors. Statistical level of significance was set at 0.05 . Best-corrected visual acuity mea- sured by the Early Treatment Diabetic Retinopathy Study (ETDRS) chart was converted to visual acuity in LogMAR unit for purpose of analysis. Table 3 shows analysis for primary outcome. No statistically significant change in mean best-corrected visual acuity between patients of all 3 groups in each follow-up $(p=0.891)$.
Analysis within steroid group showed statistically significant change in mean best=corrected visual acuity ( $p=0.002$ ). Comparing to best-corrected visual acuity in baseline, there were statistically significant improvement of best - corrected visual acuity at 1 and 3 months $(p=$ $0.015,0.028$ respectively).

Table 3 Mean best-corrected visual acuity change in 3 groups

\begin{tabular}{|c|c|c|c|c|}
\hline Primary outcome & $\begin{array}{c}\text { Progesterone } \\
n=7\end{array}$ & $\begin{array}{c}\text { Steroid } \\
\mathrm{n}=12\end{array}$ & $\begin{array}{c}\text { Otservation } \\
n=7\end{array}$ & P-value \\
\hline \multicolumn{5}{|l|}{ BCVA (LogMAR) } \\
\hline Beseline & $1.67 \pm 0.39$ & $1.66 \pm 0.32$ & $1.59=0.31$ & 0.891 \\
\hline $1 \mathrm{wk}$ & $1.54=0.60$ & $1.44 \pm 0.52$ & $1.40+0.56$ & \\
\hline $1 \mathrm{Mo}$. & $1.49 \pm 0.62$ & $1.26 \pm 0.61$ & $1.40 \pm 0.53$ & \\
\hline $3 \mathrm{Mo}_{\mathrm{:}}$ & $1.40 \pm 0.69$ & $1.28 \pm 0.66$ & $1.41 \pm 0.54$ & \\
\hline P-value (within group) & 0.055 & $0.002^{*}$ & 0.138 & \\
\hline \multicolumn{3}{|c|}{ BCVA (LogMAR) Annlysis within steroid group } & \multicolumn{2}{|c|}{ P-value } \\
\hline Bescline & & $1.66 \pm 0.32$ & & Compare with baseline) \\
\hline $1 \mathrm{Wk}$ & & 1.4440 .52 & & 0.053 \\
\hline $1 \mathrm{Mo}_{2}$ & & $1.26 \pm 0.61$ & & $0.015^{*}$ \\
\hline $3 \mathrm{Mo}$. & & $1.28 \pm 0.66$ & & $0.028 *$ \\
\hline
\end{tabular}

Secondary outcomes for this study were color vision tested by Ishihara test and visual field testing, focused on mean deviation and pattern standard deviation. Analysis for these secondary outcomes Table 4 showed no significant change in number of plate of ishihara test, mean deviation and pattern standard deviation $(p=0.415,0.826$, 0.330 respectively).

Table 4 Mean best-corrected visual acuity change in 3 groups

\begin{tabular}{|c|c|c|}
\hline Secondary outcomes & Progesterone, $n=7$ & P-value \\
\hline \multicolumn{3}{|l|}{ Color vision by Lshihara test (Plates) } \\
\hline Baseline & $0.00=0.00$ & 0,415 \\
\hline $1 \mathrm{Wk}$ & $1.71 \pm 4.54$ & \\
\hline $1 \mathrm{Mo.}$ & 35749.45 & \\
\hline $3 \mathrm{Mo}$. & 3.5749 .45 & \\
\hline \multicolumn{3}{|l|}{ Visual field (Mean deviation) } \\
\hline Baseline & $-31.95 \div 3.92$ & 0.826 \\
\hline $1 \mathrm{wk}$ & $-31.96 \pm 3.15$ & \\
\hline $1 \mathrm{Mo.}$ & $-30.25 \pm 7.93$ & \\
\hline $3 \mathrm{Mo}$, & $-30.22+9.63$ & \\
\hline \multicolumn{3}{|l|}{ Visual field (Pattern standard deviation) } \\
\hline Baseline & $2.11+0.45$ & 0.330 \\
\hline $1 \mathrm{wk}$ & $3.25 \div 2.53$ & \\
\hline 1 Mo. & $3.18 \pm 2.88$ & \\
\hline $3 \mathrm{Mo}$ & $2.68+2.59$ & \\
\hline
\end{tabular}

Improvement of visual acuity was defined as a decrease of at least $0.4 \log$ MAR in visual acuity after 3 months (Decreased BCVA in LogMAR unit reflects better BCVA). Table 5 shows factors effecting visual outcomes on recovery of visual acuity, analyzed by Binary logistic regression analysis. Most of clinical characteristics showed no effect to improvement of visual acuity. Better baseline best-corrected visual acuity was the only factor detected statistically significant to predict better visual outcome $(p=0.027$, Odds ratio $=0.004,95 \% \mathrm{CI}=0.000-0.537$ ). 
Table 5 Factors effecting visual outcomes

\begin{tabular}{|c|c|c|c|c|c|}
\hline Facters & Improved (e-s) & $\begin{array}{l}\text { Net improved } \\
(m=17)\end{array}$ & Pvalue & Odds ratio & 9wcL. \\
\hline \multicolumn{6}{|l|}{ Groupe, ats) } \\
\hline Progestervase & $2028.6)$ & $s(7, A)$ & 1900 & 1.000 & $0.098-10.106$ \\
\hline Steremid & श्र41. & r(58.3) & 0.37 & 1.786 & $0.241-13215$ \\
\hline Ondervalion & 208.69 & $s(7, A)$ & & 1.000 & \\
\hline Buscline BCVA & $1.38+0.04$ & $1.78+0.16$ & $0.027^{*}$ & 0.004 & $0.000-0.597$ \\
\hline $\mathrm{Age}$ & $25.56+5.48$ & $34.78+18.22$ & 0.174 & 094 & $0.881-1.003$ \\
\hline \multicolumn{6}{|l|}{ Sex } \\
\hline Male & $9075)$ & $1962.5)$ & 0999 & NA & NA \\
\hline Female & (x) & $2(1000)$ & & 1.000 & \\
\hline \multicolumn{6}{|l|}{ side ot oye } \\
\hline Riguta cye & 397.59) & $5(62.5)$ & 0.837 & 1.200 & $0.212-6.201$ \\
\hline Left we & (003.3) & $12(66.7)$ & & 1.000 & \\
\hline \multicolumn{6}{|l|}{ Injug bype } \\
\hline Vohicks asciblent & $8(4.4)$ & $10(55.6)$ & & 1.000 & \\
\hline Fall & (x) & $4(100)$ & a999 & NA & NA \\
\hline Assublt & m(0) & $2(100)$ & 9999 & NA & NA \\
\hline Blast & I60) & 1(30) & 0.881 & 1.250 & $0.067-23239$ \\
\hline \multicolumn{6}{|l|}{ Oribial fichoures } \\
\hline No fiactare & $(42.9)$ & $8(57.1)$ & 0.251 & 3000 & $0.459-19.9 n$ \\
\hline I wall & 1(30) & 1(30) & 6392 & 4.000 & $0.167-95.785$ \\
\hline$>1$ walls & 2200) & s(60) & & 1.000 & \\
\hline \multicolumn{6}{|l|}{ Hisisory of emnesia } \\
\hline Yos & 708.99 & 1166.1) & 0.496 & 1.909 & $0.297-12.261$ \\
\hline No & 2(25) & $6(73)$ & & 1.000 & \\
\hline Thene to visit heppital & $7.67+7.75$ & $6.12+6.01$ & 0.362 & 1.037 & $0.917-1.172$ \\
\hline Time to tratument & $50.86 \div 42.04$ & $79.67 \div 51.36$ & 0.219 & ases & $0.965-1.008$ \\
\hline
\end{tabular}

$\mathrm{BCVA}=$ Best-corrected visual acuity, $95 \% \mathrm{CI}=95 \%$ confidence interval, NA = not applicable

\section{Discussion}

In our study, most of cases were young men, which is consistent with other studies. ${ }^{(7,39)}$ Vehicle accidents were the most common form of injury in our patients ${ }^{(18)}(69.2 \%)$, as they were in the studies of Entezari et al. ${ }^{(40)}(51.5 \%)$ and Steinsapir et al. ${ }^{(41)}(45 \%)$

Visual improvement occurred in $28.6 \%$ of cases in progesterone group, $41.7 \%$ of steroid and $28.6 \%$ of observation groups; this difference was not statistically significant. Moreover, there was no statistically significant change in mean best-corrected visual acuity between patients of all 3 groups in each follow-up ( $p$-value $=0.891)$. Therefore, our study showed that there was no difference in improvement effect between progesterone, steroid and observation in the treatment of indirect traumatic optic neuropathy. Our results were relevant to those found by Levin et al. ${ }^{(7)}$, which reported results of treatment of 127 cases with TON by observation alone, with corticosteroid treatment, or optic nerve decompression surgery. The results did not show any differences in study groups $(32 \%$ in the decompression group, $57 \%$ in the placebo group, and $52 \%$ in the treatment group). In Levin's study, selection of cases was also not randomized and the trial was not double-blind.
Analysis within steroid group showed statistically significant change in mean best-corrected visual acuity $(p-$ value $=0.002)$. Comparing to best-corrected visual acuity in baseline, there were statistically significant improvement of best- eorrected visual acuity at 1 and 3 months ( $p$ - value $=0.015,0.028$ respectively). This result that found in our study contrasts to Entezari's study ${ }^{(40)}$ which reported that corticosteroid administration in TON does not improve visual acuity compared to placebo administration ( $p$-value $=0.38)$. In terms of secondary outcome, the results failed to show the improvement of color vision and visual field testing despite of the selected case of patient number 1 .

Progesterone treatment in our study showed no side effect detected by symptom and laboratory results. This finding resembles report the use of progesterone in treatment of traumatic brain injury by Wright et $\mathrm{al}^{(36)}$ and Xiao et al. ${ }^{(37,38)}$

These reports confirm that treatment by progesterone is safe and reflects interesting outcomes. In our study, some of patients received steroid prior to progesterone due to physician's judgement. These events also showed no adverse effect of both medications which imply that progesterone can be used adjunct or combine to steroid treatment. At some circumstance, patients may be contraindicated to corticosteroid treatment; progesterone can be a main or alternative choice of treatment for patient with indirect traumatic optic neuropathy.

After multivariate analysis, only one factor was detected to be statistically significant in our study. Initial BCVA was detected as a predictive factor in improvement of final BCVA. This is similar to Levin's study ${ }^{(7)}$, in which they concluded that initial visual acuity after trauma is a powerful prognostic factor in final visual acuity. This relation was also detected in other studies. ${ }^{(42,43)}$

Our study shows that progesterone is a safe and promising neuroprotective agent for treatment of indirect traumatic optic neuropathy. Our study was the first to report about clinical use, efficacy and safety of progesterone for traumatic optic neuropathy treatment but showed no difference among choices of treatment. The study design was historical control trial which had problems in validity, time frame for comparison and missing data. To prove a clear effect, we suggest conducting double-blind randomized clinical trial studies with different doses of progesterone and study in larger population. 


\section{References}

1. Pirouzmand F. Epidemiological trends of traumatic optic nerve injuries in the largest Canadian adult trauma center. J Craniofac Surg 2012; 23: 516-20.

2. Anderson RL, Panje WR, Gross CE. Optic nerve blindness following blunt forehead trauma. Ophthalmology 1982; 89: 445-55.

3. Walsh FB. Pathological-clinical correlations: I. Indirect trauma to the optic nerves and chiasm. II. Certain cerebral involvements associated with defective blood supply. Invest Ophthalmol 1966; 5: 433-49.

4. Carta A. Ferrigno L, Salvo M, Bianchi-Marzoli S, Boschi A, Carta F. Visual prognosis after indirect traumatic optic neuropathy. J Neurol Neurosurg Psychiatry $2003 ; 74: 246-8$.

5. Bracken MB, Shepard MJ, Hellenbrand KG, Collins WF, Leo LS, Freeman DF. Methylprednisolone and neurological function, 1 year after spinal cord injury. Results of the National Acute Spinal Cord Injury Study. J Neurosurg 1985; 63: 704-13.

6. Young W, Bracken MB. The Second National Acute Spinal Cord Injury Study. J Neurotrauma 1992; Suppl 1: S397-405.

7. Leonard A. Levin, Roy W. Beck, Michael P. Joseph, Stuart Seiff, Raymond Kraker. The Treatment of Traumatic Optic Neuropathy:The International Optic Nerve Trauma Study. Ophthalmology 1999;106:1268- 77 .

8. Baulieu E, Robel P. Neurosteroids: a new brain function? Journal of Steroid. J Steroid Biochem Mol Biol 1990; 37: 395-403.

9. Stein DG. Progesterone exerts neuroprotective effects after brain injury. Brain Res Rev 2008: 57: 386-97.

10. Schumacher M, Robel P, Baulieu EE. Development and regeneration of the nervous system: a role for neurosteroids. Dev Neurosci 1996; 18: 6-21.

11. Roof RL, Duvdevani R, Braswell L, Stein DG. Progesterone facilitates cognitive recovery and reduces secondary neuronal loss caused by cortical contusion injury in male rats. Exp Neurol 1994; 129: 64-9.

12. Roof RL, Duvdevani R, Heyburm JW, Stein DG. Progesterone rapidly decreases brain edema: treatment delayed up to 24 hours is still effective. Exp Neurol. 1996; 138: 246-51.
13. Roof RL, Duvdevani R, Stein DG. Progesterone treatment attenuates brain edema following contusion injury in male and female rats. Restor Neurol Neurosci 1992; 4: 425-7.

14. Roof RL, Hoffiman SW, Stein DG. Progesterone protects against lipid peroxidation following traumatic brain injury in rats. Mol Chem Neuropathol 1997; 31: 1-11.

15. Wright DW, Bauer ME, Hoffiman SW, Stein DG. Serum progesterone levels correlate with decreased cerebral edema after traumatic brain injury in male rats. J Neurotrauma 2001; 18: 901-9.

16. Schumacher M, Baulieu EE. Neurosteroids: synthesis and functions in the central and peripheral nervous systems. Ciba Found Symp 1995; 191: 90-106.

17. Stein DG. Brain damage, sex hormones and recovery: a new role for progesterone and estrogen? Trends Neurosei 2001; 24: 386-91.

18. Stein DG, Roof RL, Fulop ZL. Brain damage, sex hormones and recovery. In: Stuss DT, Winocur G, Robertson $\mathrm{IH}$, eds. Cognitive Neurorehabilitation: A Comprehensive Approach. Cambridge, Cambridge University Press; 1999. p.73-93.

19. Baulieu EE. Neurosteroids: a new function in the brain. Biol Cell 1991; 71:3-10.

20. Koenig HL, Schumacher M, Ferzaz B, Thi AN, Ressouches A, Guennoun R, et al. Progesterone synthesis and myelin formation by Schwann cells. Science 1995; 268: 1500-3.

21. Behl C, Trapp T, Skutella T, Holsboer F. Protection against oxidative stress-induced neuronal cell death: a novel role for RU486. Eur J Neurosci 1997; 9: 912-20.

22. Mayo W, Dellu F, Robel P, Le Moal M, Baulieu EE, Simon $\mathrm{H}$. Infusion of neurosteroids into the nucleus basalis magnocellularis affects cognitive processes in the rat. Brain Res 1993; 607: 324-8.

23. Jiang N, Chopp M, Stein D, Feit H. Progesterone is neuroprotective after transient middle cerebral artery occlusion in male rats. Brain Res 1996; 735: 101-7.

24. Betz AL, Coester HC. Effect of steroid therapy on ischaemic brain oedema and blood to brain sodium transport. Acta Neurochir Suppl (Wien) 1990; 51: 256-8.

25. McEwen BS, Coirini H, Westlind-Danielsson A, Frankfurt M, Gould E, Schumacher M. Steroid hormones as mediators of neural plasticity. J Steroid Biochem Mol Biol 1991; 39: 223-32. 
26. Sugino $N$, Shimamura $K$, Tamura $H$, Ono M, Nakamura $\mathrm{Y}$, Ogino $\mathrm{K}$, et al. Progesterone inhibits superoxide radical production by mononuclear phagocytes in pseudopregnant rats. Endocrinology 1996; 137: 749-54.

27. Duvdevani R, Roof RL, Fulop Z, Hoffiman SW, Stein DG. Blood-brain barrier breakdown and edema formation following frontal cortical contusion: does hormonal status play a role? J Neurotrauma $1995 ; 12$ : 65-75.

28. Attella MJ, Nattinville A, Stein DG. Hormonal state affects recovery from frontal cortex lesions in adult female rats. Behav Neural Biol 1987; 48: 352-67.

29. Hunt JS, Miller L, Roby KF, Huang J, Platt JS, DeBrot BL. Female steroid hormones regulate production of pro-inflammatory molecules in uterine leukocytes. J Reprod Immunol 1997; 35: 87-99.

30. Gonzalez-Vidal MD, Cervera-Gaviria M, Ruelas R, Escobar A, Morali G, Cervantes M. Progesterone: protective effects on the cat hippocampal neuronal damage due to acute global cerebral ischemia. Arch Med Res 1998; 29: 117-24.

31. Asbury ET, Fritts ME, Horton JE, Isaac WL. Progesterone facilitates the acquisition of avoidance learning and protects against subcortical neuronal death following prefrontal cortex ablation in the rat. Behav Brain Res 1998; 97: 99-106.

32. Thomas AJ, Nockels RP, Pan HQ, Shaffrey CI, Chopp M. Progesterone is neuroprotective after acute experimental spinal cord trauma in rats. Spine 1999; 24: 2134-8.

33. Djebaili M, Guo Q, Pettus EH, Hoffman SW, Stein DG. The neurosteroids progesterone and allopregnanolone reduce cell death, gliosis, and functional deficits after traumatic brain injury in rats. J Neurotrauma 2005; 22:106-18.

34. Djebaili M, Hoffman SW, Stein DG. Allopregnanolone and progesterone decrease cell death and cognitive deficits after a contusion of the rat pre-frontal cortex. Neuroscience 2004; 123: 349-59.
35. Pettus EH, Wright DW, Stein DG, Hoffman SW. Progesterone treatment inhibits the inflammatory agents that accompany traumatic brain injury. Brain Res 2005; 1049: 112-9,

36. Wright DW, Kellermann AL, Hertzberg VS, Clark PL, Frankel M, Goldstein FC, et al. ProTECT: a randomized clinical trial of progesterone for acute traumatic brain injury. Ann Emerg Med 2007; 49: 391-402.

37. Xiao GM, Wei J, Wu ZH, Wang WM, Jiang QZ, Cheng J. Clinical study on the therapeutic effects and mechanism of progesterone in the treatment for acute severe head injury. Zhonghua Wai Ke Za Zhi 2007; 45: 106-8.

38. Xiao G, Wei J, Yan W, Wang W, Lu Z. Improved outcomes from the administration of progesterone for patients with acute severe traumatic brain injury: a randomized controlled trial. Crit Care 2008;12: R61.

39. Alford MA, Jeffery A, Carter KD. Predictive value of the initial quantified RAPD in 19 consecutive patients with traumatic optic neuropathy. Ophthalmic Plastic Reconstr Surg 2001; 17: 323-7.

40. Entezari M, Rajavi Z, Sedighi N, Daftarian N, Sanagoo M. High-dose intravenous methylprednisolone in recent traumatic optic neuropathy; a randomized doublemasked placebo-controlled clinical trial. Graefes Arch Clin Exp Ophthalmol 2007; 245: 1267-71.

41. Steinsapir KD, Goldberg RA, Sinha S, Hovda DA. Methylprednisolone exacerbates axonal loss following optic nerve trauma in rats. Restor Neurol Neurosci 2000; 17: 157-63.

42. Mauriello J, Deluca J, Krieger A, Schulder M, Frohman L. Management of traumatic optic neuropathy, a study of 23 patients. Br J Ophthalmol 1992; 76: 349-52.

43. Rajinganth MG, Gupta AK, Gupta A, Bapuraj JR. Traumatic optic neuropathy visual outcome following combined therapy protocol. Arch Otolaryngol Head Neck Surg 2003; 129: 1203-6. 